\title{
Noise Exposure Effects on Blood Glucose, Cortisol and Weight Changes in the Male Mice
}

\author{
Ebrahim Taban, ${ }^{1}$ Seyyed Bagher Mortazavi, ${ }^{2,}{ }^{*}$ Shahram Vosoughi, ${ }^{3}$ Ali Khavanin, ${ }^{2}$ and Hassan Asilian \\ Mahabadi $^{2}$ \\ ${ }^{1}$ Faculty of Medical Sciences, Tarbiat Modares University, Tehran, IR Iran \\ ${ }^{2}$ Department of Occupational Engineering, Faculty of Medical Sciences, Tarbiat Modares University, Tehran, IR Iran \\ ${ }^{3}$ Department of Health Sciences, Faculty of Health, Safety and Environment, Shahid Beheshti University of Medical Sciences, Tehran, IR Iran \\ "Corresponding author: Seyyed Bagher Mortazavi, Department of Occupational Engineering, Faculty of Medical Sciences, Tarbiat Modares University, Tehran, IR Iran. Tel: \\ +98-9123562471, E-mail: mortazav@modares.ac.ir
}

Received 2016 January 06; Revised 2016 February 09; Accepted 2016 February 12.

\begin{abstract}
Background: Noise is one of the most important hazardous factors in industrial environments. Noise has many important negative effects on health; it can cause damage auditory, visual, neurological and psychological and hormonal systems, and physiological and cognitive functions.

Objectives: The current study aimed to investigate the effects of noise exposure on changes in glucose and cortisol serum levels in adult male mice.

Methods: A total of 24 adult male mice were randomly divided into two experimental and one control groups. One of the experimental groups was exposed to a noise pressure level of $90 \mathrm{~dB}$ played by Cool Edit software on a computer in a frequency range 700 $5700 \mathrm{~Hz}$, and the other one was exposed to the same noise and received an injection of streptozotocin (60 mg/kg). The experimental groups were exposed to the noise for 30 days, eight hours per day. Twenty-four hours after the end of the exposure period the fasting cortisol and glucose serum levels were measured in the mice of the three groups.

Results: The study results showed a significant difference in the level of glucose in non-diabetic and diabetic groups exposed to the noise, compared to the control subjects $(\mathrm{P}<0.002)$. In addition, there was a significant difference in the level of cortisol in non-diabetic and diabetic groups exposed to the noise, compared to the control groups $(\mathrm{P}<0.002)$.

Conclusions: The results showed that exposure to a $90 \mathrm{~dB}$ noise can increase cortisol and glucose levels. Hence, in work environments where people are exposed to noise, it is expected that such noises have a negative impact on them and the noise may increase cortisol and blood sugar levels.
\end{abstract}

Keywords: Noise, Cortisol, Glucose, Mice

\section{Background}

In many workplaces, workers are exposed to various occupational harmful factors that can have a negative impact on their performance and health (1). Among such factors, noise in the work environment is one of the most important factors with irreversible effects on the health of employees (2). It is estimated that more than 600 million people in the world are exposed to hazardous noise in their work environment (3). Noise can affect the human body through several ways; for instance, it can lead to auditory damage, interfere with the conversation, have negative effects on the visual organs, affect the balance system, cause neurological and psychological problems, affect electrolytes, have an impact on hormonal system and finally cause physiological and mental problems (4-7). Noise can act as a non-specific stressor inducing stress reactions, anxiety disorders, insomnia and syn- dromes of immune deregulation as well as hearing impairment (8). Some of the stressor induced alterations are attributed to an imbalance in autonomic system and involve hypothalamo-pituitary-adrenal (HPA) axis activation; this is followed by changes in neural-hormonal pathways in humans. The occupational hazardous factor is one of the environmental stressors that activate neural - hormonal pathways in humans (9). Cortisol is a hormone secreted by the body to cope with stress (10). Cortisol is the most important glucocorticoid in human body which is the final product of hypothalamus pituitary adrenal (HPA) axis (11). After the secretion of cortisol, the hormone is placed on GLUT-4 receptors and does not allow blood glucose to go into the cells; as a result, blood glucose increases. Through this mechanism, cortisol counterbalances the action of insulin $(12,13)$. Monsefi et al. showed that noise pollution can increase the level of cortisol hormone and the volume of adrenal gland in the rats. This mechanism happens 
due to the effects of noise on the hypothalamus pituitary adrenal axis (14). Another study on workers exposed to noise showed that chronic exposure to noise led to an increase in heart rhythms and increased the levels of cortisol and adrenaline (15). A study conducted on 100 workers found that chronic exposure to noise over $80 \mathrm{~dB}$ led to an increase in blood glucose and cortisol hormone (16).

A review of previous studies conducted on the effects of noise on cortisol hormone and blood sugar levels found that many of the studies were concentrated on a specific frequency. However, workers are exposed to a wide range of noise levels in their workplace and accordingly the effects of noise on them possibly are different.

\section{Objectives}

The current study aimed to evaluate the noise exposure effects on blood glucose, cortisol and weight variations in the male mice.

\section{Methods}

In the study, the tests were performed on 24 Naval medical research institute (NMRI) adult male mice purchased from Tehran Pasteur Institute, Tehran, Iran. The mice had a weight range of 25 - $35 \mathrm{~g}$ and aged 7 - 8 weeks (17). A week before the exposure, the mice were transferred to the animal shelter to cope with the environment. In the animal shelter, mice were maintained in an environment with an ambient temperature of $20-25^{\circ} \mathrm{C}$, with a humidity of $40 \%$ 50\% in 12:12 light-dark cycle; they were fed with enough water and food. At the time of exposure, the mice were adult and were more than 56 days old.

The study observed all ethical considerations about the use of laboratory animals. All of the mice were weighed and received an ID at the beginning of the experiment. Sampling was carried out in spring season. Then, in line with the type of intervention, they were randomly assigned to one of the two intervention groups ( $\mathrm{NG}=8$, NDZ $=8)$ and a control group $(C G=8)$.

Group $\mathrm{C}=$ animals with no exposure.

Group N = animals exposed to a noise exposure of 90 $\mathrm{dB}$ in a frequency range $700-5700 \mathrm{~Hz}$ for 30 days.

Group NDG = animals exposed to a noise exposure of $90 \mathrm{~dB}$ in a frequency range $700-5700 \mathrm{~Hz}$ for 30 days and became diabetic through the injection of streptozotocin (60 $\mathrm{mg} / \mathrm{kg}$ ).

Based on the results of previous studies and preliminary tests, the sample size in each group was determined as eight (18).

A noise chamber with dimensions of $30 \times 60 \times 80 \mathrm{~cm}$ was created and the floor of the chamber was set on a metal grille mesh sheet with a thickness of $5 \mathrm{~mm}$ to achieve the desired acoustic conditions; the sheet was exactly $26 \mathrm{~cm}$ away from the ceiling $(26 \times 60 \times 80 \mathrm{~cm})$. Under the floor, a sliding shelf, with a distance of $4 \mathrm{~cm}$ from the floor was created to be used to dump and remove animal waste. In the middle of the side walls, $3 \mathrm{~cm}$ above the seating place of the mice (the approximate location of the heads of mice) holes were created to measure and monitor the chamber (19).

Taking into consideration, the recommended conditions to keep animals (mice) at the time of exposure, chamber temperature was set to $25^{\circ} \mathrm{C}$ and a temperature control device was used. In case of a temperature rise, the control device sent a command to two fans installed next to the chamber and the fans started to work until the cabin temperature reached $25^{\circ} \mathrm{C}$ again. After reaching the desired temperature, the fans automatically stopped.

After making the chamber to determine the noise changes, a noise higher than the average noise pressure level $90 \mathrm{~dB}$ with the mentioned frequency was played by the Cool Edit software on a computer. The noise was generated and broadcasted to the center of the chamber through a built-in roof module. Then, the volume was measured at 12 points inside the chamber (the points were selected at heights of 3 and $10 \mathrm{~cm}$ from the floor, and six points were selected at each height). Measurements were performed using a dosimeter-sound level meter model Cel490. This device was used in the study because it had a flexible noise level meter microphone which enabled the authors to measure the noise at different parts of the closed chamber. The results of the measurements showed that the level of noise in different parts of the chamber at the desired pressure was $90 \pm 1 \mathrm{~dB}$; it verified that the noise alteration in different parts of the chamber was trivial and the noise had a very small variation.

To develop diabetes in the subjects, $60 \mathrm{mg}$ of streptozotocin (STZ) per kilogram of body weight was injected intraperitoneally (ip). To prepare an injectable solution, streptozotocin was solved in citrate buffer at a concentration of $0.1 \mathrm{M}$ and $\mathrm{pH}=4.5$. When the fasting blood glucose of the mice reached $200 \mathrm{mg} / \mathrm{dL}$, the animals were considered diabetic (20). In addition, to ensure and detect the absence of inherent diabetes, glucose urine test strips were used. After the last day of the exposure, i e, on the 29th day, and after an overnight fasting, on the 30th day at 9-11 am, the mice underwent mild anesthesia using chloroform to measure their fasting glucose. After stabilizing the animal on the dissection table and opening the chest using forceps and scalpel, blood samples were collected directly from the right ventricle. To obtain the serum, the blood samples of the mice were centrifuged for 20 minutes at $5000 \mathrm{rpm}$; to keep the serums for hormonal tests, they were stored at $-20^{\circ} \mathrm{C}$. To measure glucose, the enzyme glucose oxidase 
method was used (21) and to measure the serum cortisol level, the radioimmunoassay (RIA) was employed (20). To perform the statistical analysis, SPSS ver. 21 was used. In addition to descriptive methods, Mann-Whitney test for hypothesis testing was used.

\section{Results}

Table 1 presents the changes in serum cortisol and glucose levels and also the differences in body weights in diabetic and non-diabetic mice exposed to noise. The results of the study showed a significant difference between nondiabetic subjects that were exposed to noise and the control subjects regarding the glucose levels $(\mathrm{P}<0.002)$. In addition, there was a significant difference between diabetic subjects exposed to noise and the control subjects regarding the glucose levels $(\mathrm{P}<0.002)$. Moreover, there was a significant difference between non-diabetic and diabetic subjects exposed to noise regarding the glucose levels $(\mathrm{P}<$ 0.002).

The study results showed a significant difference between non-diabetic subjects exposed to noise and the control subjects regarding the cortisol levels $(\mathrm{P}<0.002)$. In addition, there was a significant difference between diabetic subjects exposed to noise and the control subjects regarding the cortisol levels $(\mathrm{P}<0.002)$. Moreover, there was a significant difference between non-diabetic and diabetic subjects exposed to noise regarding the cortisol levels $(\mathrm{P}<$ 0.002 ).

The weight of non-diabetic subjects exposed to noise significantly reduced, compared with that of the control subjects $(\mathrm{P}<0.001)$. The weight of diabetic subjects exposed to noise significantly reduced, compared with that of the control subjects $(\mathrm{P}<0.002)$. The weight of diabetic subjects exposed to noise sensibly reduced, compared with that of the non-diabetic subjects $(\mathrm{P}<0.002)$.

\section{Discussion}

The results of the current study showed that in nondiabetic control subjects (not exposed to noise) the measured parameters had no significant effect on cortisol and blood glucose levels. As a result of exposure to noise, the levels of serum glucose significantly changed. However, the duration of exposure in the study (i e, 30 days) did not lead to a real development of diabetes and only a pre-diabetes condition occurred. Thus, exposure to noise, which is a cause of psychological stress, can be a risk factor for diabetes in human with pre-diabetes condition or those with underlying hereditary diabetes. The results showed that the serum glucose levels increased in non-diabetic
Table 1. Effect of Noise Exposure on Glucose, Cortisol and Weight Changes in the Study ${ }^{\mathrm{a}}$

\begin{tabular}{|cccc}
\hline Group/Parameter & Weight, $\mathbf{g}$ & Glucose, $\mathbf{m g} / \mathbf{d L}$ & Cortisol, $\mu \mathbf{g} / \mathbf{d L}$ \\
\hline $\begin{array}{c}\text { Control group } \\
\text { Before } \\
\text { exposure }\end{array}$ & $30 \pm 1$ & $105 \pm 7$ & $1.0 \pm 0$ \\
\hline After exposure & $39 \pm 2$ & $106 \pm 7$ & $1.0 \pm 0$ \\
\hline Pvalue & 0.310 & 0.394 & 0.699 \\
\hline Noise group & $32 \pm 1$ & $102 \pm 5$ & $1.0 \pm 0$ \\
\hline $\begin{array}{c}\text { Before } \\
\text { exposure }\end{array}$ & $35 \pm 1$ & $169 \pm 8$ & $3.0 \pm 0$ \\
\hline After exposure & $<0.001$ & $<0.002$ & $<0.002$ \\
\hline P value & $33 \pm 1$ & $240 \pm 18$ & $1.0 \pm 0$ \\
\hline Noise-diabetes group & & & \\
\hline $\begin{array}{l}\text { Before } \\
\text { exposure }\end{array}$ & $29 \pm 2$ & $315 \pm 17$ & $5.0 \pm 0$ \\
\hline After exposure & $<0.002$ & $<0.002$ & $<0.002$ \\
\hline Pvalue & & & \\
\hline
\end{tabular}

${ }^{\mathrm{a}}$ Values are expressed as mean \pm standard error of the mean.

and diabetic subjects exposed to noise. Therefore, it can be concluded that the chronic stress in all circumstances alters the serum glucose level. The overall level of blood glucose in diabetic subjects exposed to noise was higher than that of the non-diabetic subjects; when the body is activated by a stressor, the hypothalamus is stimulated by an unknown signal to release corticotrophin - releasing hormone ( $\mathrm{CRH}$ ) which stimulates the anterior pituitary to secrete adrenocorticotrophic hormone (ACTH), considered as the hormone of stress. ACTH stimulates secretion and growth of zona fasciculate and zona reticularis of adrenal gland and stimulates the secretion of cortisol. Therefore, there is an increase in plasma cortisol level (22). However, the results showed that the level of serum glucose was approximately same in both groups after noise exposure. As a result, it can be said that exposure to intense noise can exacerbate the symptoms of diabetes and speed up the manifestation of the symptoms. In line with the current study results, Sorensen et al. reported that people living near high-traffic roads were more at risk of diabetes (23). In addition, Fezil et al. suggested that chronic exposure to noise over $80 \mathrm{~dB}$ increased blood glucose and cortisol levels (16).

Diabetic subjects exposed to noise had higher serum cortisol levels than non-diabetic subjects exposed to noise. This increase in cortisol levels in diabetic compared with non-diabetic subjects can be due to the stress of diabetes (24). Ravindran et al. showed that noise exposure that exceeds $90 \mathrm{~dB}$ is a source of stressor (25). In a study by Monsefi 
et al. conducted on rats, the subjects were exposed to noise level $100 \mathrm{~dB}$ for 30 days; the results showed an increase in serum cortisol level in the groups exposed to the noise for eight hours and twelve hours a day. They also reported a change in the size of adrenal gland (14). Goyal et al. showed that acute exposure to sound pressure level above $90 \mathrm{~dB}$ has the potential to increase cortisol secretions (6).

Ising et al. concluded that acute exposure to noise over $90 \mathrm{~dB}$ stimulated the sympathetic nervous system and increased the secretion of adrenaline and noradrenaline hormones. Besides, exposure to noise levels above $120 \mathrm{~dB}$ increased cortisol levels both in humans and animals (26). A review of the previous studies indicates that chronic noise exposure causes an increase in heart rhythms and elevates cortisol and adrenaline levels $(15,27,28)$.

Stress can cause changes in the level of secretion of hormones including the growth hormone; hence it may cause weight loss (29). On the other hand, compared with the cortisol hormone, growth hormone is substantially more sensitive to psychological stress; as a result, growth hormone has a more significant response to stress in the nervous people (30). The results of this study showed that diabetes had a larger impact on weight loss compared to the psychological stress. In the subjects with diabetes exposed to noise, the stress led to higher levels of weight loss compared to the non-diabetic subjects exposed to noise. This change indicates the cumulative effect of stress on weight loss and diabetes. Diabetes on one hand and stress on the other hand can cause hormonal and metabolic changes, and eventually lead to significant weight loss.

\subsection{Conclusion}

The current study results showed that exposure to a noise $90 \mathrm{~dB}$ in a frequency range $700-5700 \mathrm{~Hz}$ can increase cortisol and blood sugar levels. Hence, in work environments where people are exposed to noise, it is expected that such noises have a negative impact on people and the noise may increase cortisol and blood sugar levels in them.

\section{Acknowledgments}

The authors would like to express their gratitude to the honorable research deputy of Tarbiat Modares University, Tehran, Iran, for providing the facilities and conditions necessary to carry out the study.

\section{References}

1. Ljungberg JK, Neely G. Stress, subjective experience and cognitive performance during exposure to noise and vibration. J Environ Psychol. 2007;27(1):44-54.

2. Kawada T. The effect of noise on the health of children. J Nippon Med Sch. 2004;71(1):5-10. [PubMed:15129589].
3. Alberti PW. Noise, the most ubiquitous pollutant. Noise Health 1998;1(1):3-5. [PubMed:12689362].

4. Keppler H, Ingeborg D, Sofie D, Bart V. The effects of a hearing education program on recreational noise exposure, attitudes and beliefs toward noise, hearing loss, and hearing protector devices in young adults. Noise Health. 2015;17(78):253-62. doi: 10.4103/1463-1741.165028. [PubMed: 26356367].

5. Schmidt FP, Basner M, Kroger G, Weck S, Schnorbus B, Muttray A, et al. Effect of nighttime aircraft noise exposure on endothelial function and stress hormone release in healthy adults. Eur Heart J. 2013;34(45):3508-14a. doi:10.1093/eurheartj/eht269. [PubMed: 23821397].

6. Goyal S, Gupta V, Walia L. Effect of noise stress on autonomic function tests. Noise Health. 2010;12(48):182-6. doi: 10.4103/1463-1741.64976. [PubMed: 20603574].

7. Lusk SL, Hagerty BM, Gillespie B, Caruso CC. Chronic effects of workplace noise on blood pressure and heart rate. Arch Environ Health. 2002;57(4):273-81. doi: 10.1080/00039890209601410. [PubMed: 12530593].

8. Geravandi S, Takdastan A, Zallaghi E, Niri MV, Mohammadi MJ, Saki H, et al. Noise pollution and health effects. Jundishapur Journal of Health Sciences. 2015;7(1).

9. Zohar I, Weinstock M. Differential effect of prenatal stress on the expression of corticotrophin-releasing hormone and its receptors in the hypothalamus and amygdala in male and female rats. $J$ Neuroendocrinol. 2011;23(4):320-8. doi: 10.1111/j.1365-2826.2011.02117.x. [PubMed: 21306450].

10. Manenschijn L, van Kruysbergen RG, de Jong FH, Koper JW, van Rossum EF. Shift work at young age is associated with elevated long term cortisol levels and body mass index. J Clin Endocrinol Metab. 2011;96(11):E1862-5. doi:10.1210/jc.2011-1551. [PubMed: 21880805].

11. Clow A, Hucklebridge F, Stalder T, Evans P, Thorn L. The cortisol awakening response: more than a measure of HPA axis function. Neurosci Biobehav Rev. 2010;35(1):97-103. doi: 10.1016/j.neubiorev.2009.12.011. [PubMed: 20026350].

12. Broglio F, Gottero C, Prodam F, Gauna C, Muccioli G, Papotti M, et al. Non-acylated ghrelin counteracts the metabolic but not the neuroendocrine response to acylated ghrelin in humans. JClin Endocrinol Metab. 2004;89(6):3062-5. doi: 10.1210/jc.2003-031964. [PubMed: 15181099].

13. Yuen KC, Chong LE, Riddle MC. Influence of glucocorticoids and growth hormone on insulin sensitivity in humans. Diabet Med. 2013;30(6):651-63. doi:10.1111/dme.12184. [PubMed: 23510125].

14. Monsefi M, Bahoddini A, Nazemi S, Dehghani GA. Effects of noise exposure on the volume of adrenal gland and serum levels of cortisol in rat. Iran J Med Sci. 2015;31(1):5-8.

15. Tafalla RJ, Evans GW. Noise, physiology, and human performance: the potential role of effort. J Occup Health Psychol. 1997;2(2):148-55. [PubMed: 9552287].

16. Fezil M, Benson BI. Influence of occupational noise on insulin, blood glucose, homocysteine, blood pressure and heart rate. Int J Pharm Clin Sci. 2013;3(2):9-14.

17. Working PK. Male reproductive toxicology: comparison of the human to animal models. Environ Health Perspect. 1988;77:37-44. [PubMed 3289906].

18. Lund T, O’Reilly L, Hutchings P, Kanagawa O, Simpson E, Gravely $\mathrm{R}$, et al. Prevention of insulin-dependent diabetes mellitus in nonobese diabetic mice by transgenes encoding modified I-A betachain or normal I-E alpha-chain. Nature. 1990;345(6277):727-9. doi: 10.1038/345727a0. [PubMed: 2163026].

19. Barron RF. Industrial noise control and acoustics. CRC Press; 2002.

20. Tormo MA, Gomez-Zubeldia MA, Ropero F, Campillo JE. Effect of insulin and gliclazide on glucose utilization by a perfused intestinepancreas preparation isolated from diabetic and non-diabetic rats. Acta Diabetol. 1994;31(3):151-5. [PubMed: 7827354]. 
21. Kemmer FW, Bisping R, Steingruber HJ, Baar H, Hardtmann F, Schlaghecke R, et al. Psychological stress and metabolic control in patients with type I diabetes mellitus. N Engl J Med. 1986;314(17):1078-84. doi: 10.1056/NEJM198604243141704. [PubMed: 3515188].

22. Broadley AJ, Korszun A, Abdelaal E, Moskvina V, Deanfield J, Jones CJ, et al. Metyrapone improves endothelial dysfunction in patients with treated depression. J Am Coll Cardiol. 2006;48(1):170-5. doi: 10.1016/j.jacc.2005.12.078. [PubMed:16814663].

23. Sorensen M, Andersen ZJ, Nordsborg RB, Becker T, Tjonneland A, Overvad $\mathrm{K}$, et al. Long-term exposure to road traffic noise and incident diabetes: a cohort study. Environ Health Perspect. 2013;121(2):217-22. doi: 10.1289/ehp.1205503. [PubMed: 23229017].

24. Radahmadi M, Shadan F, Sadr S, Karimian SM. The effect of psychical stress on cause and exacerbation of diabetes mellitus, serum glucose and cortisol levels, and body weight in rats. J Shahrekord Uuniv Med Sci. 2004;6(1):14-25.

25. Ravindran R, Rathinasamy SD, Samson J, Senthilvelan M. Noisestress-induced brain neurotransmitter changes and the effect of Ocimum sanctum (Linn) treatment in albino rats. J Pharmacol Sci.
2005;98(4):354-60. [PubMed: 16113498].

26. Ising $\mathrm{H}$, Ising $\mathrm{M}$. Chronic Cortisol Increases in the First Half of the Night Caused by Road Traffic Noise. Noise Health. 2002;4(16):13-21. [PubMed: 12537837].

27. Lai HL, Liao KW, Huang CY, Chen PW, Peng TC. Effects of music on immunity and physiological responses in healthcare workers: a randomized controlled trial. Stress Health. 2013;29(2):91-8. doi: 10.1002/smi.2429. [PubMed: 22496093].

28. Munzel T, Gori T, Babisch W, Basner M. Cardiovascular effects of environmental noise exposure. Eur Heart J. 2014;35(13):829-36. doi: 10.1093/eurheartj/ehu030. [PubMed: 24616334].

29. Jalali M, Saki G, Sarkaki AR, Karami K, Nasri S. Effect of noise stress on count, progressive and non-progressive sperm motility, body and genital organ weights of adult male rats. J Hum Reprod Sci. 2012;5(1):48-51. doi:10.4103/0974-1208.97801. [PubMed: 22870015].

30. Roche DJ, King AC, Cohoon AJ, Lovallo WR. Hormonal contraceptive use diminishes salivary cortisol response to psychosocial stress and naltrexone in healthy women. Pharmacol Biochem Behav. 2013;109:8490. doi:10.1016/j.pbb.2013.05.007. [PubMed: 23672966]. 